\title{
TOTimals: A controlled experimental method for studying tip-of-the-tongue states
}

\author{
STEVEN M. SMITH, JEFFREY M. BROWN, and STEPHEN P. BALFOUR \\ Texas A\&M University, College Station, Texas
}

\begin{abstract}
In empirical studies of the tip-of-the-tongue (TOT) phenomenon, memory of information learned outside of the laboratory has been examined. Problems with the interpretations of such studies limit the usefulness of this technique for controlled experimentation. Such problems include insufficient control and verification of acquisition and retention factors; not knowing the intended target of the subject's memory search; and relatively low levels of observed positive TOT states. The present study demonstrates the efficacy of TOTimals-imaginary animals-for inducing TOT states. In two experiments, subjects studied a list of TOTimals and were tested for TOT states as they tried to recall the names, given the TOTimal pictures as cues. High frequencies of reported TOT states (as high as $45 \%$ ) were observed in both experiments. For unrecalled items, feeling of knowing, recognition of the name, and correct recall of the first letter were higher for names that were in TOT states than for those not in TOT states, validating the subjective TOT report. The experiments demonstrate a powerful new method for examining TOT states.
\end{abstract}

In a landmark study of tip-of-the-tongue (TOT) states, Brown and McNeill (1966) brought the phenomenon into an experimental setting by giving subjects definitions of rare words and asking for recall of the words defined. The basic method created by R. Brown and McNeill (1966) has been successfully used to study TOT states in other reported studies, including Koriat and Lieblich (1974), Kozlowski (1977), Jones and Langford (1987), and Jones (1989). A similar method was used by Yarmey (1973) and Brennen, Baguley, Bright, and Bruce (1990), who studied TOT states in the course of remembering the names of famous people.

Despite successes with the methods of naming rare words and famous people, there are some limitations and drawbacks to the use of such techniques in laboratory investigations. These include low levels of TOT states, the issue of positive as opposed to negative TOT states (in a positive TOT state, the subject believes that the target provided by the experimenter is the target that the subject has been seeking; in a negative TOT state, the subject does not believe that it is the sought-for target), and lack of control over factors related to acquisition and retention of TOT targets.

Levels of TOT states have varied among the reported experimental studies. In a review of TOT studies, A. Brown (1991) stated that TOT levels with naturalistic stimulus materials are usually about $13 \%( \pm 5 \%)$. Positive TOT levels, when reported, have been considerably lower: $3 \%-14 \%$.

Finally, if memory targets are acquired extraexperimentally, control over input and retention processes is impos-

This research was supported by NIMH Grant R01 MH4473001 awarded to Steven Smith. Correspondence should be addressed to Steven Smith, Department of Psychology, Texas A\&M University, College Station, TX 77843. sible. An experimenter cannot control or know whether or not a subject knows a target word. Likewise, the recency and frequency of encounters with the target cannot be known or verified. Furthermore, associations that the subject may have made between a target and other information cannot be manipulated.

Thus, the present experiments were motivated by the need for an experimental paradigm that can induce high levels of TOT states through the use of stimuli whose acquisition and retention can be controlled and that refer unambiguously to recall targets designated by the experimenter. In the present investigation, we created targets that were learned in the laboratory, rather than outside of it. Thus, we could control whether or not a target had been encountered, and how recent and frequent the encounters were. These targets were unambiguous in their reference; each name referred to a unique picture plus a verbal description.

The targets created and used were imaginary animals, which we will refer to as TOTimals. The choice of imaginary animals was inspired by the authors' observation that many natural TOT states occur for names and concepts that have been recently learned and that have not been frequently retrieved.

\section{EXPERIMENT 1}

The efficacy of TOTimals for inducing TOT states was tested in Experiment 1.

\section{Method}

Subjects

The 41 participants were volunteers from introductory psychology classes at Texas A\&M University.

\footnotetext{
Materials

Twelve TOTimals were created for the present study with a computer graphics program. In an attempt to approximate naturalistic materials
} 
that could be quickly learned, each stimulus consisted of a name, a picture of the imaginary animal, a brief description of the TOTimal, its size, what it eats, and where it lives. To better differentiate the stimuli, each TOTimal name had three syllables and each began with a different first letter. The descriptions, habitats, and diets were unique for each TOTimal. The TOTimals were separated into two blocks of six, to be referred to as Block A and Block B.

\section{Design and Procedure}

Acquisition. The acquisition sessions for both experiments were similar in that each involved an initial input of the TOTimals, followed by a number of test/study trials. Instructions on videotape directed the subjects to learn the imaginary animals as well as they could for a test to be explained later. Each of the six TOTimals in the first list was then shown for 15-sec apiece. After this initial input, the subjects were given two test/study trials, each consisting of a two-alternative forced-choice cued recall test, followed by the original TOTimal information. A TOTimal picture was used as a cue, with the subject making a choice between two TOTimal names. The test/study trials with the follow-up information were actually given to help ensure a strong representation of each TOTimal in memory.

List 2 was then presented and tested in the same way as List 1, except that there were four (identical) test/study trials for each item after the initial presentation of the TOTimals, rather than two as in List 1.

Recall/TOT test. After both Lists 1 and 2 had been studied and initially tested, the critical cued recall test over the TOTimal names was given. This was done either immediately after acquisition or after a 5-min delay. For the recall test the subjects were shown a picture of a TOTimal for $20 \mathrm{sec}$, during which they were instructed to indicate on their response forms the answers to four questions: (1) What is the imaginary animal's name? (2) What is the first letter of the name? (3) Would they be able to recognize the name if it were mixed in with other similarly sounding names (feeling of knowing)? (4) Are they in a TOT state? A TOT state was described as one in which the subject knew the name and felt that he or she might recall it at any time, but could not think of the name at that moment. All 12 TOTimals were tested, List 1 first and List 2 second.

Recognition test. After the recall test, the subjects were given a fouralternative forced-choice recognition test over the TOTimal names. One of the four words was the correct name of a TOTimal, and the other three were similarly sounding names. For example, the foils on the recognition test for the TOTimal named BOSHERTIN were BOSHERGEN, BANTERTIN, and BANTERGEN.

To summarize, there was one between-subjects factor (delay) and one within-subjects factor (input list). Delay was 0 or $5 \mathrm{~min}$, and input list was List 1 or 2 . List 2 had more test/study trials than did List 1 , and at the time of the recall/TOT test, List 2 was more recent than List 1.

\section{Results}

An alpha level of .05 was used for all of the statistical tests reported in both experiments.

The overall proportion of retrieval targets for which subjects reported TOT states was .25 (see Table 2). Of the 41 subjects, 35 (85\%) reported at least one TOT state. TOT rates for individual TOTimals ranged from $17 \%$ to $44 \%$.

In three one-way ANOVAs, unrecalled items in reported TOT states were compared with unrecalled items not in TOT states, using as dependent measures recall of the first letters of the names, recognition, and feeling of knowing. Significant effects were found in all three, showing that first-letter recall $\left[F(1,34)=19.27, M S_{\mathrm{e}}=.081\right]$, recognition $\left[F(1,34)=60.62, M S_{\mathrm{e}}=.069\right]$, and feeling of knowing $\left[F(1,34)=140.21, M S_{\mathrm{e}}=.042\right]$ were greater for unrecalled TOT items than for unrecalled non-TOT items (Table 1).

Three $2 \times 2$ (input list $\times$ delay) ANOVAs were computed. In one, reported incidence of TOT states was the dependent measure; in the second, it was proportion
Table 1

Feeling of Knowing, Recognition, and First-Letter Recall for Recalled, Unrecalled TOT, and Unrecalled Non-TOT TOTimal Names in Experiments 1 and 2

\begin{tabular}{|c|c|c|c|c|}
\hline \multirow[b]{3}{*}{ Experiment } & \multicolumn{4}{|c|}{ Item Type } \\
\hline & \multicolumn{2}{|c|}{ TOT } & \multicolumn{2}{|c|}{ Non-TOT } \\
\hline & $M$ & $S D$ & $M$ & $S D$ \\
\hline \multicolumn{5}{|c|}{ Feeling of Knowing } \\
\hline 1 & .93 & .15 & .35 & .24 \\
\hline 2 & .85 & .29 & .52 & .26 \\
\hline \multicolumn{5}{|c|}{ Recognition } \\
\hline 1 & .88 & .20 & .39 & .25 \\
\hline 2 & .83 & .27 & .53 & .22 \\
\hline \multicolumn{5}{|c|}{ First-Letter Recall } \\
\hline 1 & .54 & .37 & .24 & .22 \\
\hline 2 & .49 & .33 & .41 & .23 \\
\hline
\end{tabular}

Note-Chance performance on the recognition test was .25 .

Table 2

Mean Proportions of Reported TOT States, Recall Rates, and Recognition Rates as a Function of Input List 1 and List 2 Practice in Experiment 2

\begin{tabular}{|c|c|c|c|c|c|c|c|c|}
\hline \multirow[b]{4}{*}{ Experiment } & \multicolumn{4}{|c|}{ First } & \multicolumn{4}{|c|}{ Second } \\
\hline & \multicolumn{8}{|c|}{ List 2 Practice } \\
\hline & \multicolumn{2}{|c|}{ High } & \multicolumn{2}{|c|}{ Low } & \multicolumn{2}{|c|}{ High } & \multicolumn{2}{|c|}{ Low } \\
\hline & $M$ & $S D$ & $M$ & $S D$ & $M$ & $S D$ & $M$ & $S D$ \\
\hline \multicolumn{9}{|c|}{ TOT } \\
\hline 1 & .32 & .26 & & & .19 & .25 & & \\
\hline 2 & .45 & .28 & .37 & .32 & .21 & .28 & .33 & .28 \\
\hline \multicolumn{9}{|c|}{ Recall } \\
\hline 1 & .29 & .30 & & & .64 & .27 & & \\
\hline 2 & .14 & .17 & .15 & .27 & .49 & .27 & .33 & .28 \\
\hline \multicolumn{9}{|c|}{ Recognition } \\
\hline 1 & .91 & .13 & & & .96 & .10 & & \\
\hline 2 & .89 & .17 & .89 & .14 & .96 & .08 & .93 & .08 \\
\hline
\end{tabular}

Note-Chance performance on the recognition test was .25 .

recalled, and in the third, proportion recognized. The mean reported proportions of TOT states are shown in Table 2.

The proportion of TOT states was significantly higher for the first presented list of TOTimals than for the second list $\left[F(1,39)=6.82, M S_{\mathrm{e}}=.050\right]$. The effect of delay, however, was not significant $\left[F(1,39)=1.25, M S_{\mathrm{e}}=\right.$ $.080]$, nor was there a delay $\times$ input list interaction $\left[F(1,39)=.02, M S_{\mathrm{e}}=.050\right]$.

The mean proportion of the TOTimals correctly recalled was .47 (Table 2). ${ }^{1}$ Recall was significantly higher for the second presented list than for the first $[F(1,39)=$ 59.36, $\left.M S_{\mathrm{e}}=.042\right]$. There was no effect of delay on recall $\left[F(1,39)=.06, M S_{\mathrm{e}}=.14\right]$, nor was there a delay $X$ input list interaction $\left[F(1,39)=.02, M S_{e}=.042\right]$.

Recognition memory performance was extremely high, with a mean overall proportion correct of .93 (Table 2 ). Recognition performance was significantly greater for List 2 than for List $1\left[F(1,39)=8.53, M S_{\mathrm{e}}=.007\right]$. There was no effect of delay on recognition $[F(1,39)=$ $\left..59, M S_{\mathrm{e}}=.019\right]$, nor was there a delay $\times$ input list interaction $\left[F(1,39)=1.15, M S_{\mathrm{e}}=.007\right]$. 


\section{Discussion}

Very high rates of TOT states were reported, higher than the positive TOT rates found in previously reported experimental studies. The highest reported rate of positive TOT states for extraexperimentally learned targets was .14 (Yarmey, 1974); the average rate in Experiment 1 was .25.

Evidence was found in support of the idea that reported TOT states were genuine TOT experiences, rather than whimsical subjective reports. First, it was found that subjects were more confident of their memories of unrecalled TOT items than of unrecalled non-TOT names, as shown by the feeling-of-knowing scores. Second, and perhaps more compellingly, it was found that objective measures of memory for unrecalled items (first-letter recall and recognition memory) were greater for unrecalled TOT names than for non-TOT names.

\section{EXPERIMENT 2}

Our primary objective in Experiment 2 was to replicate and extend our findings of high levels of valid TOT states with the TOTimals procedure used in Experiment 1.

\section{Method}

\section{Subjects}

The 61 participants were volunteers from introductory psychology classes as before.

\section{Materials \\ The materials were those used in Experiment 1.}

\section{Design and Procedure}

The 12 TOTimals were presented and initially tested in almost exactly the same way as in Experiment 1, with a few exceptions. The first list was presented and initially tested twice, as in Experiment 1 . The second list was then studied and tested either once or three times. The target list was tested either first or last. The TOTimals used in List 1 and List 2 were counterbalanced, using Block $A$ for half of the groups and Block B for the other groups. There were three between-subjects variables: List 2 practice (one vs. three test/study trials), test order (List 1 first vs. List 2 first), and list counterbalancing. The one within-subjects variable was input list (List 1 vs. List 2).

\section{Results}

The overall TOT rate, across all experimental conditions, was . 34 (see Table 1). Of the 61 subjects, 56 (92\%) reported at least one TOT state. TOT rates for individual TOTimals ranged from $18 \%$ to $50 \%$.

In three one-way ANOVAs, unrecalled names in TOT states were compared with unrecalled names not in TOT states. In one, feeling-of-knowing scores were the dependent measure; in another, it was recognition hits; and in a third, first-letter recall. The means for these results are shown in Table 1.

Recognition $\left[F(1,53)=23.81, M S_{\mathrm{e}}=.067\right]$ and feeling of knowing $\left[F(1,53)=52.87, M S_{\mathrm{e}}=.049\right]$ were significantly greater for unrecalled items in TOT states than for those not in TOT states. First-letter recall of TOT and non-TOT items showed the same trend but did not reach significance $\left[F(1,53)=2.22, M S_{\mathrm{e}}=.074\right]$.

Three $2 \times 2 \times 2 \times 2$ (List 2 practice $\times$ test order $\times$ list counterbalancing $\times$ input list) ANOVAs were computed. In one, proportion of TOT states was the dependent measure; in another, it was proportion recalled; and in a third, proportion recognized.
For the TOT analysis, the only significant main effect was that of input list $\left[F(1,53)=10.98, M S_{\mathrm{e}}=.059\right]$. The first input list elicited many more reported TOT states (.415) than did the second input list $(.268)$.

The analysis of recall scores, like the TOT analysis, revealed significant effects of input list $[F(1,53)=59.84$, $\left.M S_{\mathrm{e}}=.037\right]$; the second input list was recalled better than the first.

The analysis of recognition hits revealed one significant effect, that of input list $\left[F(1,53)=5.92, M S_{\mathrm{e}}=\right.$ $.015]$. The second input list was recognized better than the first (see Table 2).

\section{Discussion}

In Experiment 2, the high rate of valid TOT states found in Experiment 1 was replicated. During recall of the first input list of TOTimals, the subjects reported TOT states in $41 \%$ of the cases. This is a higher TOT rate than has been reported in any previous study. As in Experiment 1 , subjects were confident that they knew names in cases in which they reported TOT states, as indicated by the feeling-of-knowing scores. Objective memory measures-recognition and first-letter recall-showed that subjects had greater knowledge of unrecalled TOT items than of unrecalled non-TOT items.

\section{GENERAL DISCUSSION}

We believe that the methodology used in the present study is important for at least three reasons. Foremost is that retrieval of recently learned TOTimal names was an extremely effective way to induce high levels of valid TOT states in the laboratory. Second, our methodology permits us to observe TOT states in relation to manipulable factors that have not been previously controllable in laboratory settings. Third, the use of newly learned named concepts, such as the TOTimals created for the present study, helps bridge the gap between the need for controllable stimuli and the desire to examine more meaningful, naturalistic materials that can relate to subjects' knowledge bases.

\section{REFERENCES}

Brennen, T., Baguley, T., Bright, J., \& Bruce, V. (1990). Resolving semantically induced tip-of-the-tongue states for proper nouns. Memory \& Cognition, 18, 339-347.

Brown, A. S. (1991). A review of the tip of the tongue experience Psychological Bulletin, 109, 204-223.

Brown, R., MCNeILl, D. (1966). The " tip-of-the-tongue" phenomenon. Journal of Verbal Learning \& Verbal Behavior, 5, 325-337.

JoNES, G. V. (1989). Back to Woodworth: Role of interlopers in the tip-of-the-tongue phenomenon. Memory \& Cognition, 17, 69-76.

Jones, G. V., \& LANGFORD, S. (1987). Phonological blocking in the tip of the tongue state. Cognition, 26, 115-122.

Koriat, A., \& Lieblich, I. (1974). What does a person in a "TOT" state know that a person in a "don't know" state doesn't know. Memory \& Cognition, 2, 647-655.

KozLowskI, L. T. (1977). Effects of distorted auditory and of rhyming cues on retrieval of tip-of-the-tongue words by poets and nonpoets. Memory \& Cognition, 5, 477-481.

YARMEY, A. D. (1973). I recognize your face but I can't remember your name: Further evidence on the tip-of-the-tongue phenomenon. Memory \& Cognition, 1, 287-290.

\section{NOTE}

1. Recall of a TOTimal name was counted as correct only if the spelling was $100 \%$ accurate.

(Manuscript received April 26, 1991.) 